\title{
Developing a World Flora Online - a 2020 challenge to the world's botanists from the international community
}

\author{
Peter Wyse Jackson ${ }^{1,2}$ \& James S. Miller ${ }^{1}$
}

\begin{abstract}
The Global Strategy for Plant Conservation of the Convention on Biological Diversity adopted as its first target in 2010 the preparation of "An online flora of all known plants" by 2020. This target was subsequently adopted by a broadly-based international consortium of botanical institutions that have committed themselves to undertaking this ambitious project. The preparation of a world flora will be the first modern and large-scale and comprehensive attempt to produce a comprehensive overview and baseline of knowledge on the world's plant diversity. This article outlines previous historic efforts to document the world's known flora. It also describes the ways in which the World Flora Online Consortium was created, how it is organized and its plans to compile diverse datasets available in digital formats into a single online portal available and open to all. Such data are being combined from geographical floristic accounts, such as the Flora of China, the Flora of North America and many other regional and national projects, together with relevant monographic treatments.
\end{abstract}

Key words: Biodiversity, conservation, Global Strategy for Plant Conservation, taxonomy, world flora.

\begin{abstract}
Resumo
A Estratégia Global para a Conservação das Plantas e a Convenção da Biodiversidade adotaram em 2010, como a primeira meta para 2020, a produção de uma flora online de todas as espécies conhecidas. Tal meta foi assumida por um amplo grupo de participantes provenientes de diversos institutos botânicos e esta comunidade comprometeu-se a atingir essa meta. O primeiro Consórcio da Flora On-line foi criado com a finalidade de

preparação de uma flora mundial moderna e em larga-escala, provisionando a primeira tentativa de produzir uma estrutura para embasar a totalidade do conhecimento botânico mundial. O presente artigo expõe esforços históricos prévios realizados para documentar a flora do mundo, assim como a presente organização do Consórcio da Flora Online, cujo objetivo é compilar diversas bases de dados disponíveis em formatos digitais distintos num portal de acesso aberto ao público. Os dados estão sendo combinados a partir de tratamentos regionais distintos, como a Flora da China, Flora da América do Norte e muitos outros projetos regionais e nacionais, combinados a monografias relevantes.

Palavras-chave: Biodiversidade, Conservação, Estratégia Global para a Conservação das Plantas, Taxonomia, Flora Mundial.
\end{abstract}

\section{Overview}

In 2002 the Convention on Biological Diversity (CBD) adopted a Global Strategy for Plant Conservation (GSPC), with the aim of halting the loss of plant diversity worldwide. It has now been endorsed by almost all of the countries of the world, and was renewed and updated on $29^{\text {th }}$ October, 2010 for the period up to 2020 by decision $\mathrm{x} / 17$ of the Conference of the Parties to the Convention on Biological Diversity. Incorporating 16 global targets, the Strategy includes within its objectives the need to document and understand plant diversity, to provide a baseline of knowledge on which plant conservation actions can be based.

The Global Strategy for Plant Conservation was developed within the context of a serious crisis impacting on plant diversity worldwide. There are estimated to be approximately 300,000 known vascular plant species, perhaps another 50,000-100,000 await discovery (Joppa et al. 2010; Miller 2011). Currently there are known to be approximately 100,000 plant species that are

\footnotetext{
${ }^{1}$ Missouri Botanical Garden, P.O. Box 299, St. Louis, MO 63166-0299, U.S.A.

${ }^{2}$ Author for correspondence: Peter.Wysejackson@mobot.org
} 
threatened by extinction in the wild. Preservation, management, and sustainable use of the world's biological resources is critical to maintain a careful balance between nature and development; otherwise, we will lose forever the biodiversity that supports us and our environment. Today, the world's biodiversity is being reduced at an accelerating rate without regard to its actual use and the potential it holds. Plants provide the basis for all terrestrial ecosystems and are a fundamental requirement in the maintenance of ecosystem services on which our survival depends.

The rationale for the development of the GSPC was that plants are universally recognized as a vital part of the world's biological diversity and an essential resource for the planet. In addition to the small number of crop plants used for basic food and fibers, many thousands of wild plants have great economic and cultural importance and potential, providing food, medicine, fuel, clothing and shelter for vast numbers of people throughout the world. Plants play a key role in maintaining the planet's basic environmental balance and ecosystem stability and provide an important component of the habitats for the world's animal life. A driver for the development of the GSPC was the concern that many are in danger of extinction, threatened by habitat transformation, over-exploitation, alien invasive species, pollution and climate change. It was recognized that the potential disappearance of such vital and large amounts of biodiversity sets one of the greatest challenges for the world community: to halt the destruction of the plant diversity that is so essential to meet the present and future needs of humankind. The global strategy for plant conservation was proposed to address this challenge. While the entry point for the strategy is conservation, aspects of sustainable use and benefit-sharing are also included (Wyse Jackson \& Kennedy 2009).

As recognized in the GSPC, there is a tremendous need for a comprehensive documentation resource on the world's plant species, as a baseline to guide conservation effort and for plant resource planning and management. Information on the world's plants is presently dispersed in hundreds of journals and thousands of books, and indeed is by no means complete. It is generally retrieved by geographic location in various Floras that cover particular regions, which vary from small sites to continental. But the geographic ranges of plant species generally don't often conform with geo-political boundaries, so Floras don't usually present a complete set of information about the species that are included. There are also monographic works that do cover individual plant groups, generally genera or, less frequently, families, in a comprehensive manner. But there is only up-to-date information for a small percentage of the world's plant genera. As a consequence of the dispersed nature of available literature, it is often difficult for secondary users of information about plants to find what they need. The conservation community, for example, cannot easily retrieve information about the conservation status or comprehensive geographic distributional information of plants. Recent efforts to scan historical literature about plants and make it available electronically via the internet, such as the Biodiversity Heritage Library (<http://www. biodiversitylibrary.org/ $>$ ), have improved access to the relevant literature, but it is still generally necessary to consult large numbers of references to retrieve any comprehensive information for the plants of a particular area.

\section{History of Global Plant Inventories}

Historically, many early botanists made efforts to comprehensively catalog the world's plants. When the Swedish botanist, Carl Linnaeus (1707-1778) published Species Plantarum in 1753 , it did in effect aim to be a world flora, but Linnaeus only knew about just short of 6,000 species in about 1,000 genera, a tiny percentage of the c.300,000 species known today. Linnaeus eventually expanded his knowledge to cover about 7,700 species of plants and believed that the world had no more than 10,000 species (Davis \& Heywood 1973). The successors to Linnaeus built upon his work and their efforts greatly increased the known number of plant species but, within about a hundred years, the number was becoming insurmountable for an individual botanist to handle in a single publication, even in multiple volumes. The work of Augustin Pyramus De Candolle (17781841), a Swiss botanist (born in France), was among the last efforts to comprehensively catalog the world's flora. His Prodromus Systematis Naturalis Regni Vegetabilis, widely known simply as the Prodromus, began in 1824 and eventually ran to 17 volumes, some published by other botanists after De Candolle's death (he was personally only able to finish seven volumes). It was near comprehensive for the time in relation to plant species known, but 
a few parts were never completed. Collectively, the volumes of the Prodromus provide treatment for 58,975 species of Dicotyledons and Gymnosperms (Davis \& Heywood 1973). The monocots and the genus Ficus were never completed though. Near the end of the 19th century, Adolf Engler (1844-1930), a German botanist, began two monumental works intended to cover the whole plant kingdom. Die Naturlichen Pflanzenfamilien, which he started in 1887 with his colleague Karl Prantl (1849-1893), provided a summary of plant families and genera and Das Pflanzenreich, from 1900 onwards, was a series of detailed generic monographs. Engler and his collaborators completed much of this work, but by the time they were working the number of plant species had grown so much that neither work was comprehensive when he passed away in 1930 (Davis \& Heywood 1973). Following Engler, the number of known plant species had grown to a point where it was no longer considered an approachable project for traditional publication and subsequent botanists generally restricted publications to individual groups of plants or plants of regions substantially smaller than the whole world.

\section{Major Regional Plant Inventories}

Notable milestones in early regional completed plant inventories include The Flora of West Tropical Africa (Hutchinson \& Dalziel 1954-1972), prepared and published by the Royal Botanic Gardens, Kew, completed in 1936, world's first completed tropical regional flora. The revised second edition, covering 7,072 species in 1,742 genera, was finished in 1972. Another floristic milestone was Flora Europaea (Tutin et al. 1964-1980), a five volume comprehensive overview of the plants of Europe published between 1964 and 1993, the first continental Flora published. More recently the completion of The Flora of China (Wu \& Raven 1994-2013) represented another such milestone. The Flora of China was a 25 year an international collaborative project begun in 1988 to publish a comprehensive catalog of all Chinese wild vascular plants, with full descriptions of 31,500 species and illustrations of about 20,000 species. The first volume appeared in 1994 and, by March of 2013, 22 volumes of text and 22 volumes of illustrations have been published. The Flora of China was jointly published by the Missouri Botanical Garden Press (St. Louis) and Science Press (Beijing).

The last 50 years have seen our knowledge of the plant kingdom grow to where there are presently about 300,000 known and accepted plant species (Prance et al. 2000; Miller 2011). These have been described via both floristic and monographic works and most parts of the world have had significant floristic activity in recent years so information on most of the world's plants is there to be synthesized. Yet collectively the information is highly dispersed in the literature. But in the last 30 years, the assembly of various electronic databases and the development of the software to run them has again made the possibility of a comprehensive catalog of plants possible. Today the information exists to be compiled from modern floras and its rigorous review by specialists on various plant groups is an approachable project. The tools and content to produce a World Flora Online, called for in Target 1 of the Global Strategy for Plant Conservation, exist today.

\section{The Delivery of Target 1 of the GSPC, a World Flora Online}

The first phase of the Global Strategy for Plant Conservation, up to 2010, included as its first target to prepare "A working list of known plant species, as a step towards a complete world flora". This target was completed through the collaboration of the Missouri Botanical Garden with the Royal Botanic Gardens, Kew, U.K. when 'The Plant List' was launched at the end of $2010(<\mathrm{http}$ ://www. theplantlist.org/ $>$ ). This represented the culmination of major efforts made by both institutions and many other organizations too, to bring together multiple projects into this first ever global checklist. It aims to be comprehensive for species of Vascular plant (flowering plants, conifers, ferns and their allies) and of Bryophytes (mosses and liverworts). It does not include algae, fungi or plants only known as fossils. Version 1.1 of The Plant List was released in September 2013. It replaced Version 1.0 and included new data sets, updated versions of the original data sets and improved algorithms to resolve logical conflicts between those data sets. 'The Plant List' provides the accepted Latin name for most species, with links to all synonyms by which that species has been known. Around 20\% of plant names are still unresolved, indicating that the data sources included provided no evidence or view as to whether the name should be treated as accepted or not, or there were conflicting opinions that could not be readily resolved. It is fully recognized that 'The Plant List' has limitations and that quality of content varies from one plant group to another in a 
manner reflective of our present state of knowledge and what contributions were included. The Plant List is clearly a work in progress that aims to be a 'best effort' list, to demonstrate progress and to stimulate further work. 'The Plant List' includes $1,064,035$ scientific plant names of species rank. Of these $350,699(33.0 \%)$ are accepted species names. $470,624(44.2 \%)$ names included are synonyms and $242,712.22(22.8 \%)$ are unresolved. It currently contains contributions from the Royal Botanic Gardens, Kew, the Missouri Botanical Garden, Global Compositae Checklist, the International Legume Database and Information Service (ILDIS), the Royal Botanic Gardens, Edinburgh, the South African National Botanical Institute, Conservatoire et Jardin Botanique, Ville de Genève.

A key tool used by the Missouri Botanical Garden to support its plant systematic research is the Tropicos $®$ database (<http://www.tropicos. $\operatorname{org} />$ ), which will be a fundamental resource for

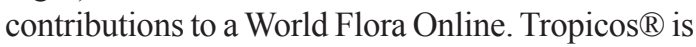
the world's largest database of plant identification information, containing extensive research information for over 1.2 million plant names and over 4 million plant specimens. It is based upon and incorporates nearly 30 years of scientific research and data compilation by Garden staff and many others. Thousands of scientists at the Garden and around the world depend upon it to support their research in plant and conservation science. Botanical information from Tropicos represents a key component of the data content of 'The Plant List'.

When the GSPC was updated in 2010, a new $1^{\text {st }}$ target was adopted, to prepare "An online flora of all known plants" by 2020 (<https://www.cbd. int/gspc/strategy.shtml $>$ ). The World Flora Online (WFO) is a critical initiative required in order to meet the world's needs for knowledge on which to base plant conservation, ecological restoration and to sustain human use of plant species for a multitude of socio-economic purposes. It will also provide a fundamental resource to clarify where conservation needs are greatest and what gaps in knowledge exist.

In January 2012 in St Louis, Missouri, U.S.A., representatives from four institutions: the Missouri Botanical Garden, the New York Botanical Garden, the Royal Botanic Garden Edinburgh, and the Royal Botanic Gardens, Kew - all members of the Global Partnership for Plant Conservation (GPPC) $(<\mathrm{http}: / /$ www.plants2020.net $>$ ) took the initiative to meet and discuss how to achieve GSPC Target 1 by 2020 . The meeting resulted in a proposed outline of the scope and content of a World Flora Online, as well as a decision to form an international consortium of institutions and organizations to collaborate on providing that content (<https://www.cbd.int/doc/ meetings/sbstta/sbstta-16/information/sbstta-16inf-38-en.pdf $>$ ).

The World Flora Online project was subsequently launched in India, at an event held during the 11th Conference of the Parties (COP) to the Convention on Biological Diversity in October, 2012 where the COP also adopted a decision welcoming the World Flora Online initiative:

The $11^{\text {th }}$ Conference of the Parties of the Convention on Biological Diversity "Welcomes the initiative of the Missouri Botanical Garden, the New York Botanical Garden, the Royal Botanic Garden, Edinburgh, and the Royal Botanic Gardens, Kew, and their partner organizations and supporters worldwide, to lead the development of a "World Flora Online" by 2020 to facilitate the achievement of Target 1 of the Global Strategy for Plant Conservation. (UNEP/CBD/COP/DEC/ $\mathrm{XI} / 26)(<\mathrm{https}$ //www.cbd.int/doc/decisions/cop-11/ cop-11-dec-26-en.pdf $>$ ).

In January, 2013, a Memorandum of Understanding (MOU) for the World Flora Online was opened for signature. As of the end of August 2015, 29 institutions and organizations had signed the MOU, becoming part of the project and members of the World Flora Online Consortium (<http://www. worldfloraonline.org/>) (Tab. 1). A range of other institutions and organizations worldwide is also being invited to participate in the WFO Consortium.

Through the MOU, a WFO Council was created, including representatives from each of the members of the Consortium. Council Members have met regularly since 2012: at the Missouri Botanical Garden (July 2012), the Royal Botanic Garden, Edinburgh (November 2013), the Komarov Institute, St. Petersburg, Russia (June 2014), and the Conservatoire et Jardin Botanique, Ville de Genève (February 2015) (Miller et al. 2014). Future meetings are currently planned for Rio de Janeiro (October 2015), New York (early 2016), and Capetown, South Africa (Fall 2016). The Council currently comprises 29 member institutions (Tab. 1) and is chaired by Peter Wyse Jackson, President of the Missouri Botanical Garden. Initially structured with four working groups including Governance, Technology, Taxonomy, and Data Gathering, there has been no continuing need for the Governance working group and the latter two have been combined. 
Table 1 - Members of the World Flora Online Consortium*

Australian Biological Resources Study Canberra, Australia

Botanic Garden and Botanical Museum, Berlin-Dahlem, Dahlem Centre of Plant Science (DCPS), Berlin, Germany

Botanic Garden Meise, Belgium

Conservatoire et Jardin Botaniques, Genève, Switzerland

Flora Iberica Project, Madrid, Spain

Flora of North America Association, US \& Canada

Forest Research Institute Malaysia, Kuala Lumpur, Malaysia

Global Biodiversity Information Facility, Copenhagen, Denmark

Institute of Botany, Academy of Sciences of the Czech Republic, Prague, Czech Republic

Institute of Botany, Azerbaijan National Academy of Sciences. Baku, Azerbaijan

Institute of Botany, Chinese Academy of Sciences Beijing, China

Institute of Botany, Slovak Academy of Sciences Bratislava, Slovakia

Instituto de Botánica Darwinion, Buenos Aires, Argentina

Instituto de Pesquisas Jardim Botânico do Rio de Janeiro Rio de Janeiro, Brazil

Instituto Nacional de Biodiversidad (INBio), Costa Rica

Komarov Institute of Botany, Russian Academy of Sciences, St. Petersburg, Russia

Kunming Institute of Botany, Chinese Academy of Sciences, Kunming, China

Missouri Botanical Garden, St. Louis, Missouri, USA

Muséum National d'Histoire Naturelle, Paris, France

Natural History Museum, London, UK

Naturalis Biodiversity Center, Leiden, Netherlands

Royal Botanic Garden Edinburgh, Edinburgh, UK

Royal Botanic Gardens, Kew, London, UK

Smithsonian National Museum of Natural History, Washington, DC, USA

South African National Biodiversity Institute, Pretoria, South Africa

The New York Botanical Garden, New York, NY, USA

Botany Department of Trinity College Dublin, Dublin, Ireland

Tsitsin Main Botanical Garden, Russian Academy of Sciences, Moscow, Russia

UNESCO Chair in Plant Conservation and Biodiversity in Macaronesia and in Western Africa Gran Canaria, Spain

* Members, as of $31^{\text {st }}$ May, 2015

Currently the Technology working group is chaired by Chuck Miller (Missouri Botanical Garden) and Mark Watson (Royal Botanic Garden, Edinburgh) and the Taxonomy working group is chaired by Thomas Borsch (Berlin-Dahlem Botanical Garden) and David Simpson (Royal Botanic Garden, Kew).

\section{Scope and Content of the World} Flora Online

The World Flora Online is planned to be an open-access, web-based compendium of the world's plant species. The World Flora Online will consist of a nomenclatural backbone, placing all names not accepted in proper synonomy. Associated with the name of each accepted species will be descriptions, primarily from previously published works, illustrations, photos, conservation assessments when available, and other information. Descriptions and keys will also be included with families and genera. Information to be included has been discussed at each of the previous WFO Council meetings and the target audiences anticipated to benefit from consulting the WFO are summarized in Table 2. 
It was agreed in the earliest organizational meetings that it would be impossible to generate new information, particularly descriptions, for the approximately 300,000 currently known plant species therefore it would need to rely primarily on existing descriptions, distributional information and identification tools. In line with The Plant List, the focus of the WFO will be on comprehensive species level information for species of Vascular plant (flowering plants, conifers, ferns and their allies) and of Bryophytes (mosses and liverworts), but not including algae, fungi or plants only known as fossils. Already very extensive data are held by a wide variety of botanical organizations and institutions worldwide which can be incorporated to provide a solid basis for the WFO development. For example, the Missouri Botanical Garden can contribute information that results from more than 40 years of activity in efforts to complete floristic inventories of various parts of the world. This will include contributions from the Flora of North America, Flora Mesoamericana, Flora of the Venezuelan Guayana, Flora of China, the Madagascar Catalog (including the other islands of the SW Indian Ocean), and checklists of Ecuador, Peru, Bolivia, and the South American Southern Cone (Argentina, Chile, Paraguay, and Uruguay).

Another example of existing data of value to the WFO project is the eMonocot project, led by the Royal Botanic Gardens, Kew (RBG Kew) (<http://e-monocot.org/>). eMonocot has been developed by a collaborative team from the

Table 2 - WFO Potential Audiences

Conservationists

Plant taxonomists

Other scientists

General interest groups

Contributors

Primary data providers

Information converters and taxonomic curators

Expert taxonomic reviewers

Technical data and systems managers

Other stakeholders

Institutional interests

Taxonomic research planners and evaluators
UK, consisting of RBG Kew, the Natural History Museum (NHM) and Oxford University. Monocots constitute approximately $23 \%$ ( 70,000 species) of all higher plants and include numerous groups with large numbers of species of economic, conservation or ecological importance (such as palms, orchids, aroids, grasses, and sedges). The objective of this project has been to produce a web-based treatment of monocot plants. The WFO Council has decided to use software prepared for eMonocot, provided by RBG Kew, for the development of a public portal for the World Flora Online.

Another important initiative relevant to the World Flora Online is The Global Plants Initiative (GPI) that is making available more than 1.8 million plant type specimens and other resources online to support floristic research around the world ( $<\mathrm{http}$ ://about.jstor.org/content/ global-plants $>$ ). In 2013, JSTOR released "Global Plants," a new community-contributed online database for scientific researchers, conservationists and others engaged in studying the world's plant biodiversity. The GPI has been a significant international undertaking by leading herbaria to digitize and make available via JSTOR plant type specimens and other holdings used by botanists and others especially those working in botany and botanical research. Funded for many years by the Andrew W. Mellon Foundation, its partners include more than 300 institutions in more than 70 countries. Founding partners include the Missouri Botanical Garden; Muséum National d'Histoire Naturelle (MNHN), Paris; The National Herbarium, Addis Ababa University; New York Botanical Garden; the Royal Botanic Gardens Kew; and the South African National Biodiversity Institute. Efforts to make digital images of type specimens for Global Plants, have also encouraged additional digitization, one major example being the work of MNHN where this herbarium has digitized over 6 million vascular plant specimens plus an additional 3 million cryptogam specimens (<http://science.mnhn.fr/ institution $/ \mathrm{mnhn} / \mathrm{search}>$ ). The team at $\mathrm{MNHN}$ also coordinated the GPI project in Francophone West Africa, including in Mauritania, Senegal, Guinea, Burkina Faso and Togo.

At national levels, many floristic treatments can also be incorporated into the World Flora Online. An example is the Flora of Nepal project that is being coordinated by the Royal Botanic Garden Edinburgh, in collaboration with the Nepal 
government's Department of Plant Resources and Tribhuvan University in Kathmandu and the University of Tokyo. The accounts of Nepal's 7,000 species are being published in ten volumes, and all this information and the data from which they have been compiled is also available through the project's website (<http://www.floraofnepal.org $>$ ).

In Brazil, the Brazilian Council for Research in Science and Technology, the Jardim Botânico do Rio de Janeiro (JBRJ) and a range of Brazil-based sponsors and other organizations are cooperating to deliver the REFLORA programme, designed to facilitate the creation of an on-line 'Flora do Brasil Digital', Brazil's response to GSPC Target 1 (<http:// reflora.jbrj.gov.br/jabot/PrincipalUC/PrincipalUC. do>; Forzza et al. 2012). To support this project several herbaria internationally are creating high resolution images of herbarium specimens of most relevance for study of the Brazilian flora and making these available to JBRJ for inclusion in the Reflora Virtual Herbarium. The Reflora Virtual Herbarium is fully integrated with the List of the Brazilian Flora first published in 2010 .

\section{Achieving the World Flora Online and} its Potential Impact

This ambitious collaborative international effort to achieve a World Flora Online will build upon existing floras, checklists, monographs, and other published research, but will also collect and generate information on poorly-known plants and plant groups and unexplored regions by engaging botanists with the most field experience and expertise in these plants or regions. The WFO will be built on a nomenclatural backbone, including all names from the International Plant Names Index (IPNI) as organized in The Plant List. This will be reviewed by taxonomic specialists for each family/genus to determine if names represent accepted species or where they should be placed in synonomy. Hopefully the percentage of unresolved names will be significantly reduced. Basic information on geographic distribution will be included. A particular emphasis will be on providing baseline data at country level, which will support the use of such information by countries implementing national-level biodiversity conservation programmes. The WFO will also include descriptions, presumably with the vast majority from previously published sources, with their source clearly identified. Keys may be included when available, but it was also agreed that dichotomous keys to large taxa with world-wide distributions are difficult if not near impossible and of limited value. Vouchered images of living plants, images of specimens, and images of illustrations will also be included. Conservation assessments will be included when available. The WFO will be primarily in English, but will include data in the languages in which it is provided. It is not intended that it will be comprehensively multi-lingual - at least in the first phases.

The WFO is not intended to provide critical, monographic treatments of all of the world's plant species, nor will it be a detailed local Flora with vouchered distributional data. Nevertheless it will provide the first widely-accessible and all-inclusive global overview of the world's plants.

It has been more than 150 years since any attempt came close to assembling a comprehensive catalog of all of the world's plant species. The WFO will provide for the first time in modern history, a single information resource that presents basic information on all of the world's plants. This will undoubtedly become the most regularly consulted resource by the world's plant research community and will probably serve the ongoing function of continuing to incorporate all new advances in plant science. But it will also serve many other important functions. For the first time ever, it will be available to the conservation community to provide information at the species level and it will be the foundation for achieving the second target of the Global Strategy for Plant Conservation, a comprehensive list of the world's threatened plant species. It is further anticipated that the WFO will also be regularly consulted as the definitive source of information on plants by broad audiences including educators, gardeners, and those interested in nature in general.

The entire botanical research community will benefit greatly from having a comprehensive information resource on the world's plants available and it would be of immediate and direct benefit to advancing research efforts. The World Flora Online will also be of immediate and benefit to the conservation community and will support vastly better efforts to ensure future survival of all plant species. The WFO Council has analyzed the potential users of the WFO (Table 2) and, through its work, it will aim to develop the project so that it addresses best the uses to which it will be put. A primary purpose is to provide the baseline of information required for the achievement of many other targets of the GSPC. For example, Target two of the Global Strategy for Plant Conservation calls for the development of a comprehensive global list of 
endangered species and this cannot be generated without a comprehensive resource on the world's plant species. The World Flora Online will also benefit any other scientific research aimed at the discovery and development of products from plants including nutritional, pharmaceutical, and agricultural products (Miller 2011).

The world continues to face extremely daunting and challenging environmental problems and many feel that human activities are triggering the largest extinction event in the history of the planet. The Global Strategy for Plant Conservation provides sixteen targets that aim to stem and control the negative impact humans are having on the planet, but achieving some meaningful success for all sixteen targets is heavily dependent on achieving targets 1 and 2, and 2 cannot be achieved without 1. While the WFO will be a great tool for plant scientists and a wonderful resource for anyone with an interest in plants, it will also be a critical tool to help meet the conservation goals essential to preserve the biological integrity of the earth.

\section{References}

Biodiversity Heritage Library. Available at $<$ http://www. biodiversitylibrary.org/>. Access on 7 July 2015.

Davis, P.H. \& Heywood, V.H. 1973. Principles and Angiosperm Taxonomy. Robert E. Krieger Publishing Company, Huntington, New York. 558p.

eMonocot. An online resource for monocot plants. Available at $<$ http://e-monocot.org/>. Access on 7 July 2015.

Flora of Nepal. Available at <www.floraofnepal.org $>$. Access on 4 August 2015.

Forzza, R.C.; Baumgratz, J.F.A.; Bicudo, C.E.M.; Canhos, D.A.L.; Carvalho Jr., A.A.; Coelho, M.A.N.; Costa, A.F.; Costa, D.P.; Hopkins, M.G.; Leitman, P.M.; Lohmann, L.G.; Lughadha, E.N.; Maia, L.C.; Martinelli, G.; Menezes, M.; Morim, M.P.; Peixoto, A.L.; Pirani, J. R.; Prado, J.; Queiroz, L.P., Souza, S.; Souza, V. C.; Stehmann, J.R.; Sylvestre, L.S.; Walter, B.M.T. \& Zappi, D.C. 2012. New Brazilian floristic list hightlights conservation challenges. Bioscience 62: 39-45.

Global Plants. Available at $<$ http://about.jstor.org/ content/global-plants $>$. Access on 7 July 2015.

Global Strategy for Plant Conservation (GSPC). Available at <https://www.cbd.int/gspc/strategy. shtml $>$. Access on 4 August 2015.
Global Strategy for Plant Conservation (GSPC). Available at $<$ http://www.plants2020.net $>$. Access on 4 August 2015.

Global Strategy for Plant Conservation (GSPC): World Flora online by 2020. Available at $<$ https://www. cbd.int/doc/meetings/sbstta/sbstta-16/information/ sbstta-16-inf-38-en.pdf>. Access on 7 July 2015.

Hutchinston, J. \& Dalziel, J.M. 1954-1972. Flora of West Tropical Africa: the British west African territories, Liberia, the French and Portuguese territories south of latitude $18 \mathrm{~N}$ to Lake Chad and Fernando Po. 3 vols. Crown Agents for Overseas Governments and Administrations, London. Vol. 1 \& 3, 2 parts, Vol. 1 part 1, pp. 1-295, part 2, pp. 297-828. Vol. 2 pp 1-544. Vol. 3 part 1, pp. 1-276, part 2, pp. 277-574.

Joppa, L.N; Roberts, D.L. \& Pimm, S.L. 2010. How many species of flowering plants are there? Proceedings of the Royal Society B: Biological Sciences 278: 554-559.

Miller, J.S. 2011. The discovery of medicines from plants: a current biological perspective. Economic Botany 65: 396-407.

Miller, J.S.; Thomas, W.W.; Watson, M.; Simpson, D. \& Wyse Jackson, P. 2014. World Flora Online Council met in St. Petersburg. Taxon 63: 959.

Muséum National d'Histoire Naturelle (MNHN). Available at $<$ http://science.mnhn.fr/institution/ mnhn/search $>$. Access on 4 August 2015.

Prance, G.T.; Beentje, H.; Dransfield, J. \& Johns, R. 2000. The tropical flora remains under-collected. Annals of the Missouri Botanical Garden 87: 67-71.

Reflora. Available at <http://reflora.jbrj.gov.br/jabot/ PrincipalUC/PrincipalUC.do $>$. Access on 4 August 2015.

The Plant List. Available at $<$ http://www.theplantlist. org/>. Access on 7 July 2015.

Tropicos ${ }^{\circledR}$ database. Available at $<$ http://www.tropicos. org/>. Access on 4 August 2015.

Tutin, T.G.; Heywood, V.H.; Barges, N.A.; Valentine, D.H.; Winters, S.M. \& Webb, D.A. 1964-80. Flora Europaea. 5 vols. Cambridge University Press, Cambridge.

World Flora Online. Available at <http://www. worldfloraonline.org/>. Access 4 August 2015.

Wu, Z. \& Raven, P.H. 1994-2013. Flora of China. 25 vols. Missouri Botanical Garden Press, St. Louis; Science Press, Beijing.

Wyse Jackson, P.W. \& Kennedy, K. 2009. The Global Strategy for Plant Conservation: a challenge and opportunity for the international community. Trends in Plant Science: Special Issue: Plant science research in botanic gardens 14: 578-580. 